\title{
MÁS ALLÁ DE LA LETRA: CUERPO Y ESCOPICIDAD EN LA POESÍA DE ANA ROSSETTI
}

\author{
Norman Marín Calderón
}

\begin{abstract}
RESUMEN
La poesía de la española Ana Rossetti (1950-) está colmada de vastos raudales de erotismo que revelan las improntas de un cuerpo erotizado plasmado en el papel de su creación. Esta relación entre el cuerpo, la escritura y el erotismo es el resultado de la subversión que nace de la palabra contra los estamentos hegemónicos vigentes. La consigna escritural de la poeta es, por ende, la de inscribir su cuerpo en el poema haciendo de su texto, sexo, y así hablar desde espacios auténticamente subjetivos. Esta escritura del cuerpo tiene lugar cuando se recuperan los placeres de los sentidos y se los plasma en el litoral entre el deseo del sexo y el goce del texto. Aquí la mirada -y su relación con la imagen, la pulsión escópica y la fase del espejo- advierte la tensión entre el placer de la carne y la inmediación con el Otro.

Palabras clave: Ana Rossetti, poesía, cuerpo, mirada, sexo, escritura, erotismo
\end{abstract}

\begin{abstract}
The poetry of Ana Rossetti (1950-) is filled with different streams of eroticism which reveal the stamp of a eroticized body expressed on her creative page. This relationship between body, writing and eroticism is the result of certain subversion that is born from words against the current hegemonic rules. Therefore, the poet's writing slogan consists of inscribing her body in the poem making her text, sex, and in that way, she can speak from authentic subjective spaces. This type of body writing takes place when the pleasure of the senses is recovered and placed in the border between the desire of the sex and the enjoyment of the text. Here gaze-and its relation to the image, the scopic drive, and the mirror stage-realizes the tense between the pleasure of the flesh and the vicinity of the Other.
\end{abstract}

Key words: Ana Rossetti, poetry, body, gaze, sex, writing, eroticism

La poesía de la española Ana Rossetti (1950-) está colmada de vastos raudales de erotismo femenino que revelan las improntas de un cuerpo erotizado que se debate entre los límites de un goce carnal que la devora y un deseo sensual que la provoca. Pareciera que cada vez que la poeta toma la pluma, cual miembro eréctil, deambulara por la página en blanco -hoja

Ph.D. Norman Marín Calderón. Profesor interino de Inglés y Teoría Psicoanalítica. Universidad de Costa Rica. Correo electrónico: normanmarin@hotmail.com

Recepción: 22- 10- 2012

Aceptación: 19- 11- 2012 
virginal- inscribiendo sobre sus pliegues carnosos, palabras henchidas de cierta sensualidad que insiste en celebrar el placer del cuerpo y la dicha de ser mujer. Esta erótica es posible en virtud del poder de los sentidos que se difumina en cada letra, en especial el poder de la vista -esos ojos que se posan para dar a la escritura su valor sexuado-. De esta manera, su escritura compromete su ser femenino a partir de una erótica inmanente, por medio de los llamados insistentes de la carne, que le devuelven una imagen alienada de su cuerpo. Y para ello se sirve del cuerpo del otro, configurando el suyo propio, ahí donde hace semblante de la inmanencia que viene de su profunda intimidad. Al escribir pareciera que tomara, al pie de la letra, la rogativa trascendente de Héléne Cixous que impele al sujeto femenino a escribir-se en el texto a través de su propio cuerpo. Ante tal llamado, su cometido escritural, es decir, su poética, será la de revelar la sexualidad del ser femenino y la de celebrar la vitalidad que viene del cuerpo en relación con el cuerpo del Otro (sexo).

La poesía de Rossetti se sirve del cuerpo erotizado de la mujer, en relación con la carne del otro, como territorio delineante en la construcción de la subjetividad femenina. Utiliza un discurso tradicional -el religioso- para entrever la sensualidad de su cuerpo y así subvertirla de manera refinada. Lo dice en "Festividad del dulcísimo nombre": "Y anulada, enamorada yo/entreabría mi boca, mientras mi cuerpo todo/tu cuerpo recibía" (1986: 70). Bajo un discurso formalmente barroco y religioso, la poeta desarticula la tradición imperante utilizando el mismo código eclesiástico - ese que tiene que ver con la Comunión como Sacramento-. Es decir, escribe utilizando todo su ser, esculpido en la página en blanco, construyendo, de esa manera, una identidad femenina que hasta ahora estuvo alienada por la intromisión de los estamentos hegemónicos. Jeanne Perreault, a este respecto asevera que "[a]lienation is not the result of creating a self in language, but instead it is alienation, from the historically imposed image of the self, that motivates the writing" (1996: 41). En este sentido, al subvertir el orden hegemónico, a través de los signos litúrgicos, eleva el poder del deseo al estatuto de discurso religioso. Esta práctica textual es también la misma formulada por Héléne Cixous en "La joven nacida" que propone que la mujer, para recobrar su propia esencia, debe de escribir su propio cuerpo, y devolver su incautación al orden patriarcal. Afirma Cixous:

Cuando la mujer deje que su cuerpo, de mil y un hogares de ardor -cuando hayan fracasado los yugos y las censuras-,articule la abundancia de significados que lo recorren en todos los sentidos, en ese cuerpo repercutirá, en más de una lengua, la vieja lengua materna de un solo surco. (2003: 547)

Lo espeta nuevamente Rossetti en la "Festividad del dulcísimo nombre" cuando hace alusión a la palabra de sus relaciones, inmanentemente sacralizada, con el cuerpo erotizado: "las más bellas palabras, asentándose iban/en mi inocente lengua./Mis primeras caricias fueron verbos,/mi amor sólo nombrarte" (las cursivas son mías, 1986: 70). Es decir, debe inscribir su cuerpo ya confiscado por la voz patriarcal y plasmarlo como suyo sobre la escritura que ella misma (se) crea con sus propios sentidos -los de la carne.

Su poesía -letra encarnada, es decir, escritura hecha carne- la escribe para cuestionar los estamentos tradicionales, los discursos hegemónicos, los constructos falologocéntricos que siempre han dictado la "Verdad" sobre el sexo y los placeres de la carne, y los escruta desde su propia perspectiva de sujeto sexuado. Esto acaece, sobre todo, por sus múltiples alusiones a la escatología judeocristiana y a la liturgia católica romana, como se discutiera en las líneas de la "Festividad del dulcísimo nombre". Así que no es casual que, bajo una doble voz, explaye lo profano bajo las máximas retóricas de lo sagrado. Lee y escribe, entre líneas, los mensajes 
subversivos que fácilmente se podrían encontrar en el discurso exegético y los rituales sacros. También allí la sexualidad se da a entender a gritos epicúreos. Así que cultura, ideología y religión son desconstruidos desde sus fundamentos para establecer una nueva perspectiva sobre el cuerpo y el sexo. Y para tal menester, emplea palabras atiborradas de infusiones insurgentes que promulgan el goce del cuerpo, la sexualidad apasionada y el disfrute de los sentidos: "ahuecado a propósito. Sonrójeme y tus dedos inician meditadas cautelas/por mi falda; demoran en los profundos túneles/del plisado y recorren las rizadas estrellas" (Rossetti 1980: 28). La escritura de Rossetti es, en definitiva, un manifiesto erotológico del placer sexual visto desde unos ojos sibaritas, llenos de la sensualidad de una mujer que disfruta de la vida y de sus placeres, sin el menor recato. Es, por lo tanto, el goce de los sentidos llenos de vigor sensual que inscribe su cuerpo sobre la página en blanco, lugar donde el verbo se hace carne.

De esta manera, el cuerpo no es sólo el objeto del deseo del Otro, sino la acción del sujeto femenino por hacer carne, es decir, "materializar" el verbo reprimido por la voz masculina imperante. "Es necesario que la mujer escriba su cuerpo, que invente la lengua inexpugnable que reviente muros de separación, clases y retóricas, reglas y códigos, es necesario que sumerja, perfore y franquee el discurso de última instancia..." (Cixous 2003: 547). Discurso y acción son modos de reprender la sintaxis patriarcal, y la mujer, a un nivel afirmatorio, se sirve de su cuerpo para darle voz a su discurso silenciado. Rossetti lo proclama en "Mis paredes, mi calma, mi vigilia": "Sacudo la tristeza que espolvorea mis sábanas/de rabia y de alfileres/Precinto con silencio la derrota./No me rindo. No entrego" (Rossetti 1995: 162). Gloria Anzaldúa, a este respecto, afirma que "for silence to transform into speech, sounds and words, it must first traverse through our female bodies" (1990: xxii). Igual lo pregona la voz poética: "sus durísimas puntas en mis dedos,/como altos pezones de muchacha./Ya conoce mi lengua las más suaves estrías de tu oreja" (Rossetti 1980: 18). Por lo tanto, la trasformación del sujeto femenino se propone a sí misma en función de la escritura de su propio ser que instaura espacios donde el cuerpo se hace tangible, es decir, en ese punto donde el ser se materializa a partir de la palabra, de la poesía -esa que se sacude y habla-.

Cuando una mujer, en vías de deshacerse de las súperimposiciones patriarcales, trata de definir su identidad personal lo hace empezando por afirmar la posesión de su propio cuerpo, ese del que es objeto y sujeto a la vez. "When defining a personal identity women tend to begin with their bodies" (Ostriker 1986: 11). El lugar de la mujer, en tanto objeto del placer del Otro, así como el sujeto, en tanto recinto de la experiencia (mundana), son plausibles sólo cuando se les explora a través del cuerpo, que funciona como el locus de cierta tensión subjetiva. La poeta lo señala cuando se refiere a los pubis angélicus:

Recorrer la ardiente miel pulida,

demorarme y, en el promiscuo borde,

donde el enigma embosca su portento,

contenerme. (Rossetti 1986: 78)

Así la poesía de Rossetti sirve como una estrategia textual por la cual su pasión por anteponer el cuerpo, como emblema de sus más caros deseos, deviene en un ser escrito, en una subjetividad discursiva, que clama una multiplicidad de formas sensoriales afirmando siempre su presencia femenina en el mundo.

De esta manera, su poesía expone un rico spectrum sobre sexualidad femenina y lo comenta sin pudor. En "Chico Wrangler", proclama: “Todo porque unas piernas, unas perfectas piernas,/dentro del más ceñido pantalón, frente a mí se separan/Se separan” (Rossetti 1985: 60). 
Se separan para mostrar el goce sicalíptico que brota de los pliegues adventicios en medio del recinto de las piernas, lugar incógnito que da a entrever el sexo que sacude el deseo hasta sus más remotos linderos. Así, se (se)paran, cual pene travieso, jugueteando entre sus muslos húmedos. De hecho, la alusión a las piernas y los muslos -sede de ese continente inexplorable que ubica la genitalidad deseada, pero censurada- es numerosa en su poesía, puesto que en medio de ellas, como quien comenta un secreto a voces, concurre la panacea del placer, ese que Coco Chanel reconoce como "el mejor de los cumplidos":

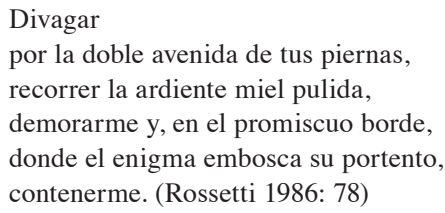

En medio de las piernas ajenas -y propias- suele encontrar el refugio a sus más ignotos misterios, y descubre en medio de ellas un goce inexplorable -goce que empieza en el punto corito de su sexualidad virtualmente consumada-. Entre sus muslos, la felicidad es inconmensurable porque es entre ellos donde el fluir de su inmanencia femenina deviene propia en virtud del deseo que nace al contacto con el cuerpo del otro: "de que una de mis manos incontenible y pálida/ siguiera resbalando/despacio, muy despacio, por mi pelvis" (Rossetti 1986: 86). Entre las de (su) hombre -cuerpo otro- su goce es portentoso a causa de este mismo goce sexual que la devora: "Fuera yo tu cintura,/fuera el abismo oscuro de tus ingles,/redondos capiteles para tus muslos fuera/fuera yo, Calvin Klein” (“Calvin Klein, Underwear”, Rossetti 1988: 128). Por lo tanto, entre sus piernas o entre las del otro, lugar del sexo, el goce inmenso del placer que viene de sus carnes - los genitales, sobre todo- provocan que su escritura devenga plegaria profana y oblación sensual sobre el cuerpo, propio y ajeno, que por la sensualidad con la que se aproxima, deviene en una sola entidad de delectación insondable. En su poema en homenaje a Lindsay Kemp, Rossetti cita a Susana Constante: "[...] el punto abultado en la entrepierna que era el foco imantado de su expectación. Preciso es decir que se trataba de una protuberancia imponente, merecedora de que se hicieran por ella los mayores disparates" (Rossetti 1980: 47). En suma, el acto escritural de Rossetti celebra una sexualidad auténtica, vital, íntima donde la letra sirve de vehículo para develar los secretos subrepticios entre sus piernas, ... y aún, más allá.

La poesía de Rossetti es una búsqueda incesante de su propio ser, ese que escudriña por todas partes, en su cuerpo y en el cuerpo "otro". Su escritura es una suerte de relación identificatoria por donde sus carnes se hacen tangibles mediante la exploración del cuerpo del otro. Lo esboza en su magistral poema "Where Is My Man?": "Nunca te tengo tanto como cuando te busco/sabiendo de antemano que no puedo encontrarte" (Rossetti 1988: 126). Escruta en el Otro las huellas perdidas de su propia subjetividad, cual espejo que dibuja su búsqueda incesante, "lunas de escaparates, laberintos de parques/o de espejos, pues corro tras de todo/lo que se te parece" (Rossetti 1988: 126). Aquí la imagen del espejo adquiere un significante valor pues es el artilugio que le devuelve la imagen de un cuerpo fragmentado, ya unificado por el deseo que habita en las profundidades de su ser. El cuerpo de mujer inquirida es tal a causa del encuentro, siempre pertinaz, con el cuerpo (deseante/deseado) del Otro. El cuerpo femenino habla a través de sus pliegues y se da a escuchar a todas voces, pero también se sirve de la carne del otro (sexo) para colocarse en un lugar de incumbencia: "toda mi piel nombrándote/toda mi piel alerta, pendiente de mis ojos" (Rossetti 1988: 126). En este instante, 
la pulsión escópica femenina entra con todas sus luces para confirmar que el cuerpo antes de escribirse, se tiene que mirar, más aún, tiene que dar(se) a ver:

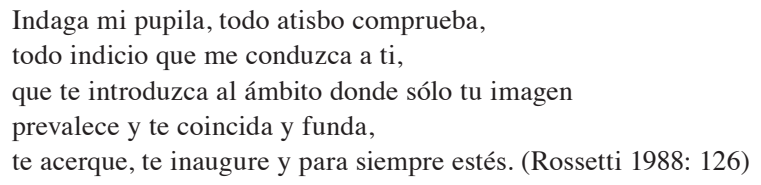

Los ojos sirven como rasgos confirmatorios del placer que se desprende al explorar las intimidades de la carne desnuda propia y la carne descubierta del otro.

Entre todos los sentidos, la mirada juega un papel relevante en la constitución de la subjetividad, sobre todo cuando se le impele ante las formas identificatorias que se establecen en relación con el cuerpo del otro (sexo). Lo espeta la poeta en "Festividad": "Flotaba mi mirada en el menstruo continuo/del incensario ardiente y mis pulsos" (Rossetti 1986: 70). El goce que experimenta la voz poética de Rossetti se exacerba cuando deviene en sujeto del deseo, o sea, sujeto de la mirada. Es a partir de la pulsión escópica por donde el ser femenino explora sus intimidades y asume su condición subjetiva en la cadena significante del deseo. Por ejemplo, al leer "Chico Wrangler", vemos cómo el sujeto femenino se agracia en la sensualidad corporal a través de la mirada penetrante que ella deposita en el cuerpo desnudo del Otro:

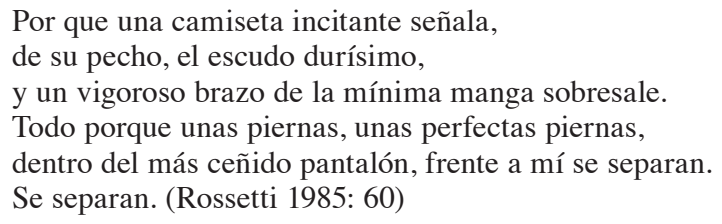

Todo este acto erótico descrito minuciosamente es el resultado voluptuoso de una cierta mirada posada en la carne anhelada del Otro. No hay señas de tocamientos, es el miramiento que anida la esperanza del goce sexual cedida al cuerpo deseante de la otra carne. Así, la poesía de Rossetti está urdida de momentos en donde la mirada se constituye como motivo del placer venido del sexo mismo. En "El jardín de tus delicias", anuncia: "asomado mi pie/provocativo, aguardo a que tú te avecines/a mi cuello, descendiendo la mirada/por el oscuro embudo de mi escote" (Rossetti 1980: 28). Por medio de la mirada es que el sujeto del deseo se constituye y recobra un lugar de goce en el circuito significante del deseo del Otro.

Así, en el instante de la mirada, el sujeto y el Otro se tornan uno por el hecho mismo de haberse mirado. La mirada hace que los dos seres sean tocados y transformados por una misma mirada de incumbencia. Jean Paul Sartre, por ejemplo, afronta la cuestión de la mirada bajo la estrategia entre "la nada y el ser-para-sí", cometido que se revela substancialmente en la poesía de Rossetti. En Lecciones psicoanalíticas, Paul Assoun interpreta este escamoteo sartreano como "mirada sobre mí, que el Otro constituye un acontecimiento y me expulsa de mí, para sî” (1995: 124). Este proceso silopsista se deja entrever entres las líneas eróticas de "Where Is My Man?": "Deliciosa congoja si creo reconocerte/me hace desfallecer: toda mi piel nombrándote,/toda mi piel alerta, pendiente de mis ojos" (Rossetti 1988: 126). Por ello, la única posibilidad de la mirada es el ser visto por el Otro. El que mira al sujeto, es siempre Otro que le interpela desde diferentes lugares, por cuanto el ser es para sí mismo. Lo interesante en la propuesta sartreana es que el ojo cumple dos funciones exclusivas por cuanto es el órgano de 
la visión (“indaga mi pupila...", Rossetti 1988: 126), pero es igualmente el soporte de la mirada ("Flotaba mi mirada [...]", "Festividad", Rossetti 1988: 70). Lacan comenta al respecto que "la mirada, tal como la concibe Sartre, es la mirada que me sorprende, y me sorprende porque cambia todas las perspectivas, las líneas de fuerza, de mi mundo y lo ordena, desde el punto de nada donde estoy, en una especie de reticulación radiada de los organismos. En tanto estoy bajo la mirada, escribe Sartre, ya no veo el ojo que me mira, y si veo el ojo, entonces desparece la mirada" (Lacan 1971: 91). Así se pasa del órgano de la vista a la pulsión escópica; lugar poético donde el ojo deviene en pura mirada.

La posición de Sartre consiste en definir el ojo como el órgano que se deposita en el objeto para mirarlo, pero una vez que la mirada ha acaecido, los ojos desaparecen para dar lugar al ser-mirado. Igual lo endosa la poeta: "Flotaba mi mirada [...] hasta el vitral traslúcido, se elevaba" (Rossetti 1986: 70). De semejante forma lo dice Sartre en El ser y la nada: "Pues percibir es mirar, y captar una mirada no es aprehender un objeto-mirada en el mundo, sino tomar conciencia de ser mirado. Así, la mirada es ante todo un intermediario que remite de mí a mí mismo" (1966: 335). Lo que significa para mí ser visto es que el objeto me mire. Es que la mirada me diga algo y haga algún efecto en mí. Por lo tanto, para Sartre, el objeto desaparece cuando me mira y los dos hacemos uno solo. La mirada convierte al sujeto y al objeto (y al Otro) en una misma figura que representa a la mirada tal cual, pues ella se basta a sí misma, tal y como sucede en la voz poética de Rossetti en muchos de sus textos. A este respecto, Lacan difiere con Sartre por cuanto el objeto le es "ajeno" al sujeto, y sólo le incumbe por el hecho mismo de que se mantiene siendo Otro. Ciertamente la mirada puede percibirse en el campo del Otro, pero se mantiene allí porque insistentemente le recuerda al sujeto su lugar en el mundo. Sujeto y Otro se encuentran y reencuentran, una y otra vez, no pudiéndose unir jamás, pues en los paralelos de su andurrial se disgregan por siempre. Rossetti lo vuelve a repetir: "De continuo te acecho [...] /sabiendo de antemano que no puedo encontrarte [...] /o de espejos, pues corro tras de todo/lo que se te parece" (Rossetti 1988: 126).

Esta mirada que se ha dispuesto para que configure el deseo femenino tiene su pertinaz propósito si se lee bajo los paradigmas de la constitución del "yo" en el estadio del espejo lacaniano. Para Lacan, el infans se torna en sujeto ante la imagen que le devuelve el espejo. En un primer tiempo, el niño se concibe como una prolongación del cuerpo de la madre quien es una en el cuerpo del infans. El espejo le ayuda a reafirmar cierta ilusión de completitud al sentirse, bajo la imagen del espejo, un sujeto fragmentado. Es decir, el estadio del espejo sostiene al niño quien se concibe a sí mismo como un ser unificado ahí donde la fragmentación le recuerda su estatuto de ser deseante. De esta misma manera, el sujeto poético de Rossetti encuentra, bajo la mirada que le devuelve el goce devorador del Otro, las improntas que le confirmen su deseo, y para esto, se sirve del artefacto del espejo. Dice en "Isolda":

\footnotetext{
Contemplo ante el espejo, hospedado en mis sábanas, las señales febriles de la noche inclemente en donde el terso lino aulaga se vertiera

y duro pedernal y cuerpo de muchacho. (Rossetti 1985: 56)
}

Así, el estadio del espejo se refiere a esa experiencia primera del infante quien descubre su propia imagen. Constituye en sí un espectáculo de "júbilo" donde el sujeto da muestras de un regocijo epifánico ante la mirada de su propia imagen en el espejo, -esa del cuerpo-mirada llena de esa energía y triunfo colosal rossettiana. 
El estadio del espejo instaura un momento de identificación primigenia por donde el sujeto sufre una suerte de trasformación estructural ante las relaciones de este con su semejante. En la fase especular, el sujeto percibe su cuerpo como una masa amorfa, desmembrada en tanto funge como siendo uno con la madre. Al admirar su cuerpo en el espejo, la imagen del individuo se descubre como una anticipación de la unidad desconocida y la motricidad perdida del cuerpo. Apunta Lacan que "el estadio del espejo es un drama cuyo empuje interno se precipita de la insuficiencia a la anticipación" (1971: 90). El espejo -como formador del yo- le indica, vía identificación, que posee un cuerpo que le pertenece y una cierta independencia con respecto a la madre -ese gran Otro. Rossetti lo promulga de diversas maneras en su poesía, y como lo había dicho: "Que te introduzca al ámbito donde sólo tu imagen/prevalece y te coincida y funda,/te acerque, te inaugure y para siempre estés" (Rossetti 1988: 126). Por ello, la visión de esta unidad, antes fragmentada, aliena al sujeto en una imagen que no es ella misma. La mirada del Otro le devuelve al individuo la "ilusión" de su propia unidad. Resulta, por lo tanto, como siendo un espejismo de sí mismo, anticipación de la maduración de su yo la cual hace del sujeto, ficción de su propia subjetividad. La poesía de Ana Rossetti explaya esta versión ficcionada de la imagen endosada por el otro:

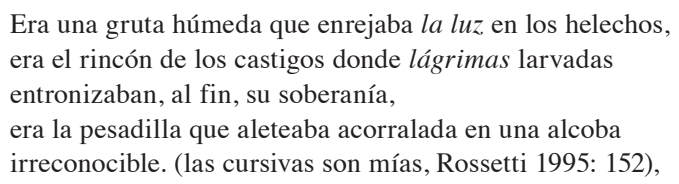

La imagen especular es, a la vez, constitutiva e ilusoria, pero necesaria para que el sujeto se separe del otro alienándose. La imagen escópica es el reflejo, pues, del propio cuerpo que se devuelve con la visión de este en el espejo, imagen que es, paradójicamente, uno mismo y el otro.

En definitiva, el cometido de Ana Rossetti, al escribir poesía, pareciera ser la descubrir la sexualidad que vagabundea por todas partes y celebrar la vitalidad que viene del cuerpo mismo: "En el rincón secreto, bajo el árbol,/despacio, muy despacio desataste mis trenzas/y luego, impetuoso, porque yo sentí frío/y terca me negaba, arrancaste mi ropa" (Rossetti 1985: 54). Esta relación entre el cuerpo, la escritura y el erotismo es la resulta de la subversión que nace de la palabra -letra sexuada- contra los estamentos hegemónicos vigentes. La consigna escritural de la poeta es, por ende, la de inscribir su cuerpo en el poema haciendo de su texto, sexo, y así hablar desde espacios auténticamente femeninos. Así lo plantea Cixous: "Escribir, acto que no sólo "realizará" la relación des-censurada de la mujer con su sexualidad, con su ser-mujer, devolviéndole el acceso a sus propias fuerzas, sino que le restituirá sus bienes, sus placeres, sus órganos, sus inmensos territorios corporales cerrados y precintados" (2003: 551). Esta puesta en acto del cuerpo femenino sobre la página poética es viable cuando se la comparte con el deseo que despunta de la íntima relación con el Otro (sexo). Rossetti celebra su cuerpo cuando se corresponde con el goce que experimenta al contacto con la carne del semejante, y bajo tal fusión, escribe poesía. Esta escritura del cuerpo tiene lugar cuando al recuperarse los placeres de los sentidos y plasmarlos en el litoral entre el deseo del sexo y el goce del texto. Aquí la mirada -y su relación con la imagen, la pulsión escópica y la fase del espejo- advierte la tensión entre el placer de la carne y la inmediación con el Otro. Por ello, el devenir de la poesía de Ana Rossetti consiste en darle voz al discurso silenciado, vivificar el cuerpo exánime, dar a ver lo oscuramente oculto, destapar lo inevitablemente censurado, en suma, es tornar la palabra amordazada en cuerpo deseante ahí donde el Verbo se hace carne. 


\section{Bibliografía}

Anzaldúa, Gloria (Ed.). 1990. Making Face, Making Soul. Haciendo Caras: Creative and Critical Perspectives by Women of Color. San Francisco: Aunt Lute.

Assoun, Paul. 1995. Lecciones psicoanalíticas sobre la mirada y la voz. Buenos Aires: Nueva Visión.

Cixous, Héléne. 2003. "La joven nacida". Textos de teoría y crítica literaria. México: Universidad Autónoma Metropolitana.

Lacan, Jacques. 1971. "El estadio del espejo en la formación del yo”. Escritos I. México: Siglo XXI.

1987. Los cuatro conceptos fundamentales del psicoanálisis. Buenos Aires: Paidós.

Ostriker, Alicia Suskin. 1986. Stealing the Language: The Emergence of Women's Poetry in America. Boston: Beacon.

Perreault, Jeanne. 1996. Writing Selves: Contemporary Feminist Autography. Minneapolis: University of Minnesota Press.

Rossetti, Ana. 1980. Los devaneos de Erato. Valencia: Prometeo.

1985. Indicios vehementes. Madrid: Hiperión.

1986. Devocionario. Madrid: Visor.

1988. Yesterday. Madrid: Torremozas.

1995. Punto umbrío. Madrid: Hiperión.

Sartre, Jean Paul. 1966. El ser y la nada. Buenos Aires: Losada. 